\title{
Standardization of whole blood immune phenotype monitoring for clinical trials: panels and methods from the ONE study
}

Mathias Streitz ${ }^{1}$, Tewfik Miloud ${ }^{2}$, Michael Kapinsky ${ }^{3}$, Michael R Reed $^{3}$, Robert Magari ${ }^{3}$, Edward K Geissler ${ }^{4}$, James A Hutchinson ${ }^{4}$, Katrin Vogt ${ }^{1}$, Stephan Schlickeiser ${ }^{1}$, Anders Handrup Kverneland ${ }^{1}$, Christian Meisel ${ }^{1}$, Hans-Dieter Volk ${ }^{1,5}$ and Birgit Sawitzki ${ }^{1,5^{*}}$

\begin{abstract}
Background: Immune monitoring by flow cytometry is a fast and highly informative way of studying the effects of novel therapeutics aimed at reducing transplant rejection or treating autoimmune diseases. The ONE Study consortium has recently initiated a series of clinical trials aimed at using different cell therapies to promote tolerance to renal allografts. To compare the effectiveness of different cell therapies, the consortium developed a robust immune monitoring strategy, including procedures for whole blood (WB) leukocyte subset profiling by flow cytometry.

Methods: Six leukocyte profiling panels computing 7- to 9-surface marker antigens for monitoring the major leukocyte subsets as well as characteristics of T cell, B cell, and dendritic cell (DC) subsets were designed. The precision and variability of these panels were estimated. The assay was standardized within eight international laboratories using Flow-Set Pro beads for mean fluorescence intensity target definition and the flow cytometer setup procedure. Standardization was demonstrated by performing inter-site comparisons.
\end{abstract}

Results: Optimized methods for sample collection, storage, preparation, and analysis were established, including protocols for gating target subsets. WB specimen age testing demonstrated that staining must be performed within 4 hours of sample collection to keep variability low, meaning less than or equal to $10 \%$ for the majority of defined leukocyte subsets. Inter-site comparisons between all participating centers testing shipped normal WB revealed good precision, with a variability of $0.05 \%$ to $30 \%$ between sites. Intra-assay analyses revealed a variability of $0.05 \%$ to $20 \%$ for the majority of subpopulations. This was dependent on the frequency of the particular subset, with smaller subsets showing higher variability. The intra-assay variability performance defined limits of quantitation (LoQ) for subsets, which will be the basis for assessing statistically significant differences achieved by the different cell therapies.

Conclusions: Local performance and central analysis of the ONE Study flow cytometry panel yields acceptable variability in a standardized assay at multiple international sites. These panels and procedures with WB allow unmanipulated analysis of changes in absolute cell numbers of leukocyte subsets in single- or multicenter clinical trials. Accordingly, we propose the ONE Study panel may be adopted as a standardized method for monitoring patients in clinical trials enrolling transplant patients, particularly trials of novel tolerance promoting therapies, to facilitate fair and meaningful comparisons between trials.

Keywords: Immune monitoring, Organ transplantation, Cell therapy, Tolerance, Kidney, Flow cytometry

\footnotetext{
*Correspondence: birgit.sawitzki@charite.de

${ }^{1}$ Institute of Medical Immunology, Charité - Universitätsmedizin Berlin,

Augustenburger Platz 1, Berlin 13353, Germany

${ }^{5}$ Berlin-Brandenburg Center for Regenerative Therapies (BCRT), Charité -

Universitätsmedizin Berlin, Berlin, Germany

Full list of author information is available at the end of the article
} 


\section{Introduction}

Immune monitoring by flow cytometry is crucial in studying effects of novel therapeutics aimed at modulating the immune response. The ONE Study consortium (www.onestudy.org) initiated a series of clinical trials to evaluate cell-based immunotherapies as adjunctive immune modulatory agents in kidney transplantation. The aim of the ONE Study is to conduct multicenter assessments of the biological effect of regulatory immune cells on recipient immune responses after transplantation in comparison to an independent clinical reference group trial using standard medication at transplant centers across Europe and the USA. The basic objective of the ONE Study is to condition the allo-specific immune response to promote protolerogenic responses to renal allografts. Different cell types with immune suppressive characteristics have been described, that are capable of modulating the allo-reactive immune response following transplantation [1-4]. Within the ONE Study trials it is planned to test naturally occurring regulatory $\mathrm{T}$ cells (nTregs) [4-8], type 1 regulatory $\mathrm{T}$ (Tr1) cells [1,9-11], tolerogenic macrophages (Mregs) [2,12,13], and tolerogenic dendritic cells (DCs) [3,14-16] predominantly for their safety in renal transplantation, but also for signs of their ability to prevent biopsy-proven acute rejection and other transplant-related pathologies, as well as their biological effects on the recipient. To be able to compare the effectiveness of these alternative cellular therapeutics, standardization of the immune monitoring assays is critical. Therefore, the ONE Study consortium developed a robust immune monitoring procedure to profile peripheral blood cellular phenotype and function of whole blood (WB) leukocytes based on flow cytometry.

Since the complexity of the immune system requires the measurement of multiple parameters in parallel and the characterization of many cell subsets, flow cytometry has become a very powerful tool for immune diagnostics $[17,18]$. However, the assay complexity in combination with a diversity of equipment, reagents, and many other pre-analytical factors such as specimen age, staining procedures, compensation, and analytical factors such as subset definition, also increases the variability, particularly when comparing results obtained within different laboratories. The variables that need to be controlled to ensure standardization have been reviewed elsewhere and different models for standardization of sample handling, instrument setup, data acquisition, and data analysis have been proposed [17-20].

Based on these principles we established robust 7- to 9-color panels for leukocyte profiling capturing the characteristics of the normal immune phenotype of different $\mathrm{T}$ cell, B cell, and DC subsets, and their activation status. The ONE Study consortium is using WB as a sample matrix to capture differences in relative and absolute cell counts of populations such as neutrophils, plasmablasts, and DCs, which are removed during peripheral blood mononuclear cell (PBMC) preparation and freezing. This approach requires rigorous control of sample collection and timing of sample preparation.

Here we describe the standardization of leukocyte profiling by flow cytometry between eight transplantation centers located in Europe and the USA for application within the ONE Study. By thorough training that requires strict adherence to standard operating procedures (SOPs), centrally defining target channels for all fluorochromes and transferring those to the cytometers at each site, we achieved comparable results with a low inter-site variability of $0.05 \%$ to $30 \%$, depending on the frequency of the cell type. This strategy is applicable for use in multicenter clinical trials, and allows detection of relative and absolute changes of nearly all blood leukocyte subsets.

\section{Methods}

All procedures were described in SOPs, and the technical staff at all sites were trained for on-site performance of the SOPs.

\section{Blood specimen collection}

Healthy individuals were recruited from staff and students of Charité - Universitätsmedizin Berlin, Berlin, Germany. Additionally, blood samples from transplant patients enrolled into the reference trial of the ONE Study were collected 3 to 6 months after kidney transplantation.

Written informed consent was obtained from all participants. The study was approved by the Ethics Committee of the Charité - Universitätsmedizin Berlin.

Blood was collected into vacutainers (BD, Heidelberg, Germany) containing EDTA for anticoagulation. Anticoagulated peripheral blood for age-of-blood test and intersite comparison was stored at $4^{\circ} \mathrm{C}$ and shipped in $4^{\circ} \mathrm{C}$ temperature-controlled boxes. For comparative analysis of different preservatives, blood was also collected into CytoChex BCT tubes (Streck labs, Omaha, NE, USA) and stored at $4^{\circ} \mathrm{C}$ for the indicated times. All consecutive blood samples were collected considering the impact of the circadian rhythm on leukocyte composition and function, as previously reported [21-24], at similar time points during the day ( \pm 1 hour).

\section{Antibody panel}

Fluorochrome-conjugated anti-human monoclonal antibodies were obtained from Beckman Coulter (Marseille, France), except anti-BDCA-2 and anti-BDCA-3, which were obtained from Miltenyi Biotec (Bergisch Gladbach, Germany), and anti-CCR7, which was obtained from R\&D Systems (Wiesbaden, Germany). Six panel matrices were defined for 7- to 9-fluorochrome channels. 
Antibody clones were chosen based on recommendation at the human leukocyte differentiation antigen (HLDA) workshops or published results. The fluorochromes for each antibody were chosen in order to achieve high sensitivity for the detection of dim antigens. Each antibody was titrated based on achieving the highest signal (mean fluorescence intensity (MFI)) for the positive population and the lowest signal for the negative population representing the optimal signal to noise ratio [25]. After optimization, all panels were formulated at Beckman Coulter. Whenever a change of the antibody batch occurred, the new formulation was tested against the old one, and was only accepted when a variability of less than $4 \%$ was achieved. Panel matrices are listed in Additional file 1: Figure S1.

\section{Leukocyte staining}

For staining protocol 1, $100 \mu \mathrm{L}$ of anticoagulated peripheral blood was stained with surface antibodies for 15 minutes at room temperature in the dark prior to lysis and fixation with VersaLyse $+2.5 \%$ IOTest fixative solution (Beckman Coulter) for 15 minutes in the dark. Lysed cells were washed twice (PBS, and PBS containing $2 \%$ FCS and $0.1 \%$ sodium azide) prior to acquisition. Prepared samples for age-of-stain tests were stored at $4^{\circ} \mathrm{C}$. For the investigation of the DC subpopulations, staining was done twice in parallel to gain sufficient cell numbers and both samples were combined before acquisition.

For staining protocol 2, for the investigation of B cell subpopulations, $300 \mu \mathrm{L}$ of anticoagulated peripheral blood was lysed with ammonium chloride (Beckman Coulter) for 12 minutes at room temperature in rotating tubes and washed twice with cold PBS. Lysed samples were stained for 20 minutes at $4^{\circ} \mathrm{C}$ in the dark, fixed with $2.5 \%$ IOTest fixative solution in PBS for 15 minutes in the dark, and washed once with PBS containing $2 \%$ FCS and $0.1 \%$ sodium azide.

The SOPs describing staining protocol 1 and 2 can be found within Additional file 2: Method S6 and Additional file 3: Method S7.

Cell staining was performed within 30 minutes, or 4 hours and 24 hours after blood collection for the ageof-blood test. Cell staining for inter-site comparisons took place simultaneously at all centers 24 or 30 hours after blood collection.

\section{Data acquisition}

All samples were measured on 10 color, 3 laser Navios flow cytometers (Beckman Coulter) using two different settings. The first setting was created with anticoagulated peripheral blood samples stained with single antibodies according to staining protocol 1. The second setting was created using pre-lysed blood stained with single antibodies according to protocol 2. Both settings and Navios protocol files were established using a single Navios at the cytometry laboratory of the Medical Immunology at Charité - Universitätsmedizin Berlin. Target channels were defined for all fluorochromes of both settings using calibration bead particles (Flow-Set Pro beads, Beckman Coulter) at the same facility. Protocol files and target channel files were forwarded to all participating flow cytometry facilities (Figure 1). Settings for all Navios cytometers were created using the target files in combination with the auto-setup function of the Navios software and the same lot of calibration bead particles as used for the creation of the settings. The relevant SOPs can be found within the Additional file 2: Method S6 and Additional file 3: Method S7. The same type of Navios flow cytometer was used at all participating sites.

\section{Validation test design}

For the inter-assay test, blood from four healthy individuals was collected and assayed on three consecutive days by two operators. Similarly, for the inter-operator test, blood from three healthy individuals was collected and assayed on two consecutive days by two operators. Within the intra-assay test, the variability in staining results of blood collected from two healthy individuals and assayed five times in parallel by one operator was determined. For the age-of-blood test, blood was taken from six healthy individuals and assayed at three different time points ( 0 hours, 4 hours, 24 hours) after blood collection by one operator. Similarly, in the age-of-stain test blood was drawn from five healthy individuals, stained in parallel, and measured at three different time points ( 0 hours, 4 hours, 24 hours) by one operator. To compare the reproducibility of the staining between different sites (inter-site comparison), blood from four healthy individuals was assayed simultaneously at five centers 30 hours after blood collection by different operators. Furthermore, to test whether immunosuppressive therapy may impact variability of leukocyte subset identification, we performed inter-operator tests on samples collected from transplant patients on three different days, which were stained by three different operators.

\section{Data analysis}

All acquired data files were analyzed by the same analyst using the Kaluza software, version 1.2 (Beckman Coulter). Cell doublets were excluded using forward scatter time of flight (wide) versus forward scatter integral (area). Leukocytes were gated using CD45 expression versus side scatter. Absolute counts of the subpopulations were calculated in all panels by use of the $\mathrm{CD} 45^{+}$ leukocyte 'backbone' in combination with the WB count obtained from all samples.

The cell subset definition and the choice of markers and dyes were discussed and defined within the ONE 


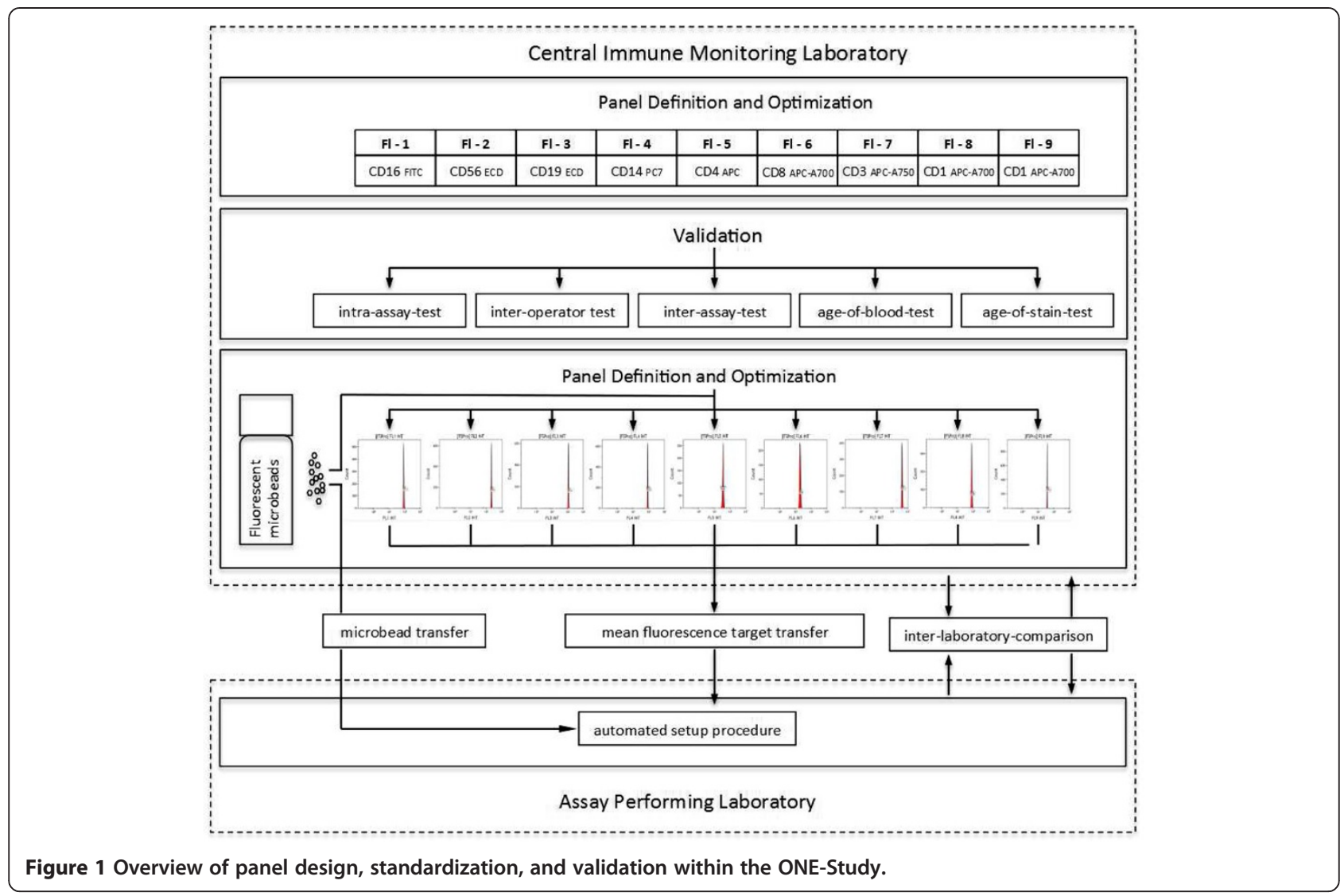

Study consortium and with Beckman Coulter. The consensus regarding the applied markers defined the gating strategy for the data analysis. To ensure correct identification of negative and positive cell populations, cells were plotted using color density bi-exponential displays, as suggested by Herzenberg et al. [26], except for the forward and sideward scatter. See also Figures 2, 3, 4, 5, 6 , and 7 for the detailed gating strategy of the different subpopulations.

For the analysis of the inter-assay test, intra-assay test, and inter-site comparison, a template analysis protocol was created for each sample and panel. Data files of the same patient and panel were analyzed by copying the data files of each time point (inter-assay test) or parallel staining (intra-assay test, inter-site comparison) into the appropriate template. Only the sideward scatter (SSC) parameter was adjusted when necessary for the 24- and 30-hour specimens.

Parameters were exported for the calculation of the size and frequencies of the subpopulations from the Kaluza software to Excel (Microsoft, Redmond, WA, USA). The precision profile approach was used to characterize the repeatability performance throughout the range of measurements [42]. Profile is a mathematical function that describes the relationship between the imprecision of the assay and the measuring range. Means and coefficients of variation (CVs) were calculated for each sample. Means of different samples represented the measuring range, while $\mathrm{CV}$ represented the corresponding repeatability performance. The relationship between mean and $\mathrm{CV}$ throughout the range of measurements was modeled as the repeatability precision profile. A power function was used to model the profiles. The choice of this function was based on the best fit of the data as well as the behavior of the cell counting at different ranges. The shape of the power function was determined by two parameters 'a' and ' $b$ ' that were estimated from the data. The model for the profiles was:

$$
C V_{i}=a \operatorname{Mean}_{i}^{b}+e_{i}
$$

where ' $\mathrm{CV}_{\mathrm{i}}$ ' and 'Mean' $\mathrm{i}_{\mathrm{i}}$ were the coefficient of variation and mean for each i-th sample, 'a' and 'b' were the parameters of the model, and ' $e_{i}$ ' was the random error. The Gauss-Newton method provided in PROC NLIN of SAS/STAT 9.3 (SAS Institute, Cary, NC, USA) was used to obtain the nonlinear least squares estimates of the parameters and their standard errors. 


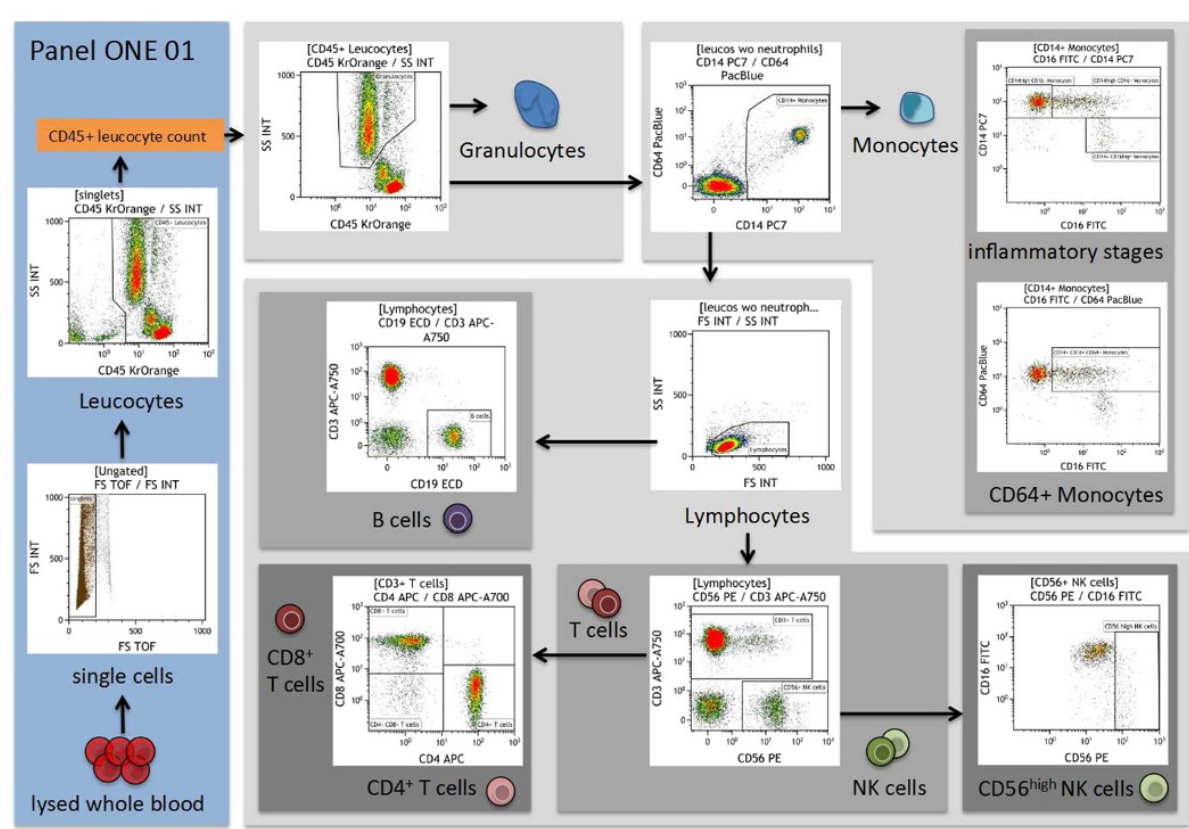

Figure 2 Overview of the gating strategy for panel ONE 01: general immune phenotype, using the sample of a healthy individual. The data file of the stained lysed (EDTA spiked) whole blood (WB) was analyzed as follows: exclusion of non-single events (forward scatter time of flight versus forward scatter integral); gating of $\mathrm{CD} 45^{+}$leukocytes (anti-CD45 versus sideward scatter integral) - the counted CD45 ${ }^{+}$events were used as the reference for calculating the absolute cell number of indicated populations in WB; gating and exclusion of granulocytes (anti-CD45 versus sideward scatter integral); gating and exclusion of all CD14 ${ }^{+}$monocytes (anti-CD14 versus anti-CD64) - the gated CD14 ${ }^{+}$monocytes were used to further discriminate different inflammatory/differentiation stages of monocytes (anti-CD16 versus anti-CD14) resulting in CD14 ${ }^{++}$CD16 classical monocytes, $\mathrm{CD} 14^{++} \mathrm{CD} 16^{+}$and $\mathrm{CD} 14^{+} \mathrm{CD} 16^{++}$monocytes, and anti-CD 16 versus anti-CD64 to capture $\mathrm{CD} 16^{+} \mathrm{CD} 64^{+}$monocytes; gating of lymphocytes (forward scatter integral versus sideward scatter integral); gating of CD56 ${ }^{+} \mathrm{NK}$ cells, which were further subdivided into CD56 ${ }^{\mathrm{dim}}$ and CD56 high NK cells; gating of CD3 ${ }^{+} \mathrm{T}$ cells (anti-CD56 versus anti-CD3) - gated T cells were used for identification of CD4 ${ }^{+} \mathrm{T}$-cells and CD8 ${ }^{+} \mathrm{T}$-cells (anti-CD4 versus anti-CD8), and the gated lymphocytes were also used for identification of the B cell population (anti-CD19 versus anti-CD3). WB, whole blood.

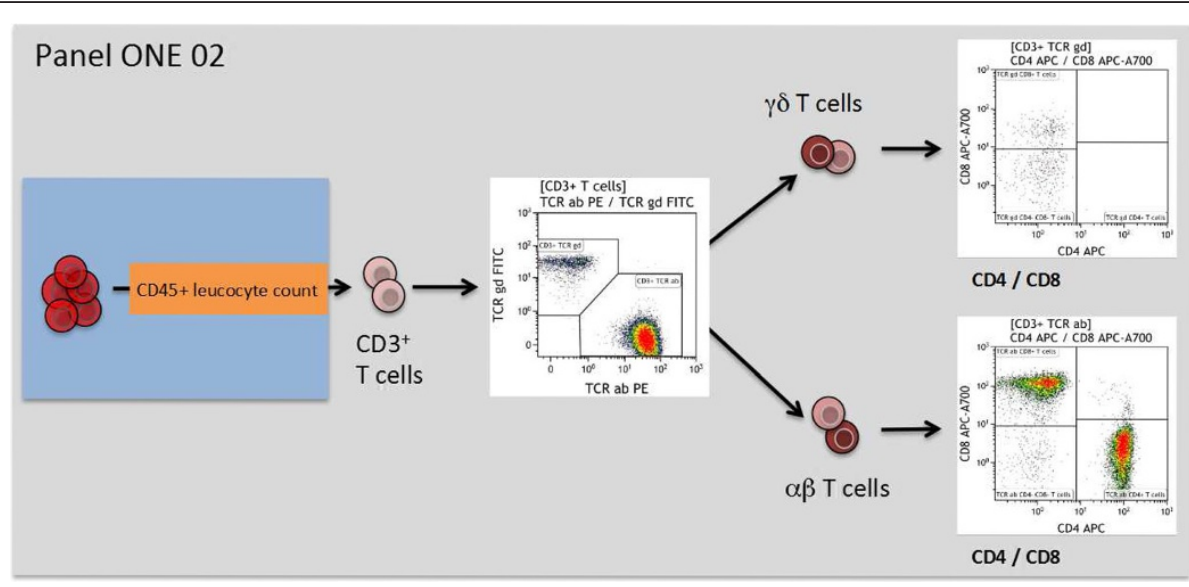

Figure 3 Overview of the gating strategy for panel ONE 02: T cell subsets/a $\beta^{+} T$ cells and $\gamma \delta^{+} T$ cells. The data file of the stained lysed (EDTA spiked) whole blood (WB) was analyzed as follows: exclusion of non-single events and gating of CD45 leukocytes as shown for panel ONE 01 (Figure 2); gating of $C D 3^{+} \mathrm{T}$ cells (anti-CD3 versus sideward scatter); gating of $\mathrm{a} \beta^{+} \mathrm{T}$ cells and $\gamma \delta^{+} \mathrm{T}$ cells (anti-T cell receptor a $\beta^{+} \mathrm{T}$ cells versus anti-T cell receptor $\gamma \delta^{+}$); and gating of $C D 4^{+}$and $C D 8^{+} T$ cells for both $T$ cell receptor subsets (anti-CD4 versus anti-CD8). WB, whole blood. 


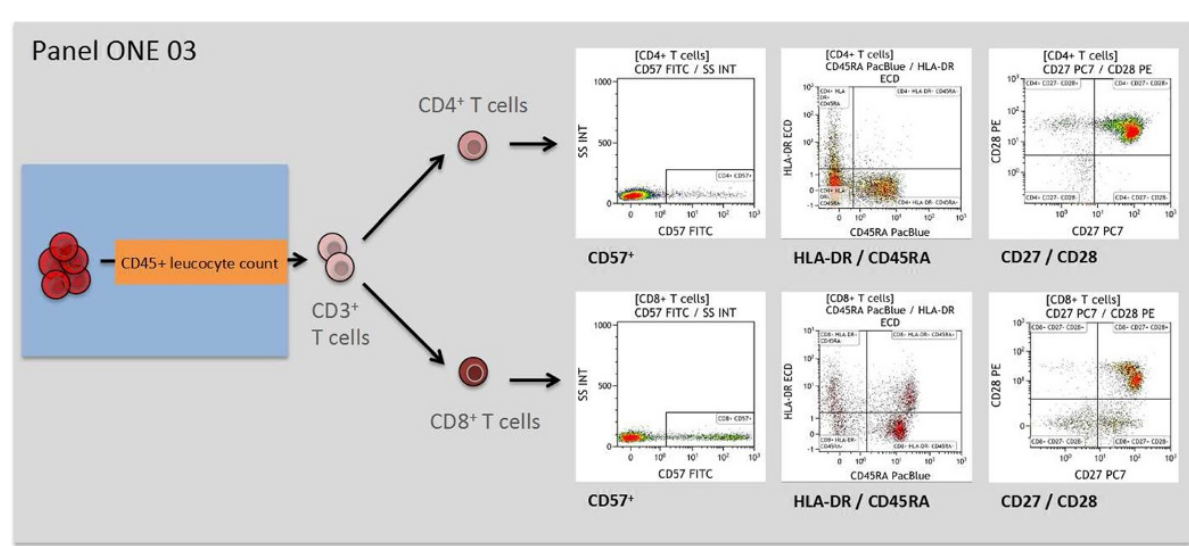

Figure 4 Overview of the gating strategy for panel ONE 03: T cell activation. Expression of CD57 or HLA-DR and loss of CD27 or CD28 expression was used as a sign of T cell activation, as previously described [27-32]. The data file of the stained lysed (EDTA spiked) whole blood (WB) was analyzed as follows: exclusion of non-single events and gating of CD45 leukocytes as shown for panel ONE 01 (Figure 2); gating of $\mathrm{CD}^{+} \mathrm{T}$ cells (anti-CD3 versus sideward scatter); and gating of $\mathrm{CD} 4^{+}$as well the $\mathrm{CD} 8^{+} \mathrm{T}$ cells (anti-CD4 versus anti-CD8), for both subsets gating

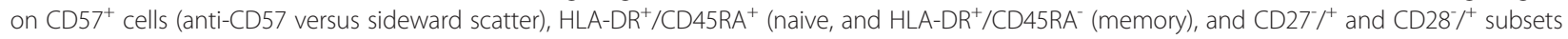
(anti-CD27 versus anti-CD28). WB, whole blood.

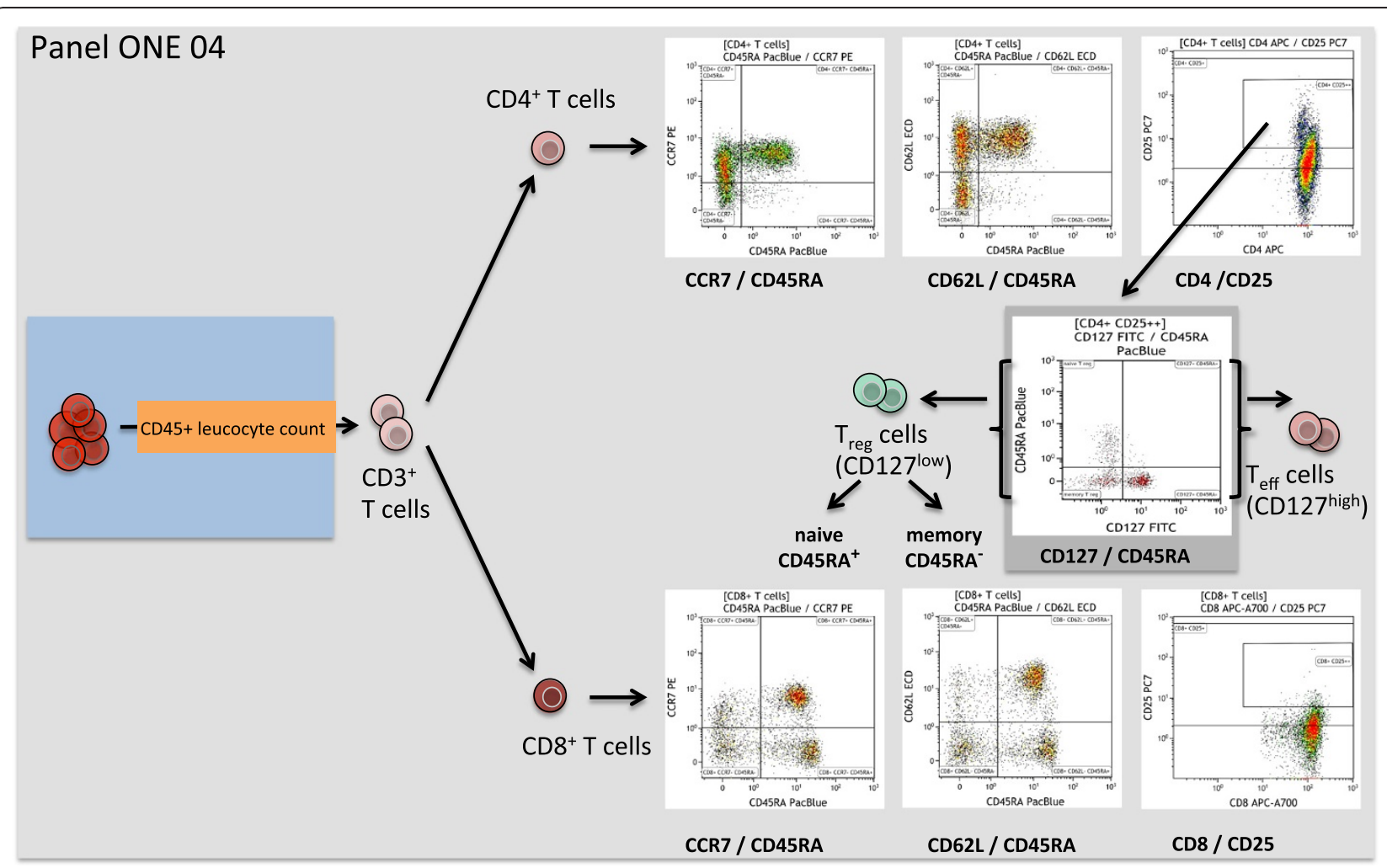

Figure 5 Overview of the gating strategy for panel ONE 04: memory T cells and regulatory T cells. The data file of the stained lysed (EDTA spiked) whole blood (WB) was analyzed as follows: exclusion of non-single events and gating of CD45 leukocytes as shown for panel ONE 01 (Figure 2); gating of $\mathrm{CD}^{+} \mathrm{T}$ cells (anti-CD3 versus sideward scatter); gating of $\mathrm{CD} 4^{+}$as well the $\mathrm{CD} 8^{+} \mathrm{T}$ cells (anti-CD4 versus anti-CD8), for both subsets gating of naive (CCR7 ${ }^{+}$or $C D 62 \mathrm{~L}^{+}$and $C D 45 R A^{+}$), central memory (CCR7 ${ }^{+}$or $C D 62 \mathrm{~L}^{+}$and $C D 45 \mathrm{RA}^{-}$), effector memory (CCR7 ${ }^{-}$or CD62 $\mathrm{L}^{-}$and $\mathrm{CD} 45 \mathrm{RA}$ ), and TEMRA (CCR7 or CD62 $\mathrm{L}^{-}$and $\mathrm{CD} 45 \mathrm{RA}^{+}$) subsets, as reported recently $[33,34] . \mathrm{CD}^{+} \mathrm{CD}^{-} 5^{++}$were further separated into CD127 ${ }^{\text {low }}$ regulatory $T$ cells, discriminating CD45RA ${ }^{+}$naive and CD45RA- memory regulatory T cells, and CD127 ${ }^{\text {high }}$ activated effector T cells [35]. We also enumerated activated $\mathrm{CD} 8^{+} \mathrm{CD} 25^{++}$cells. WB, whole blood. 


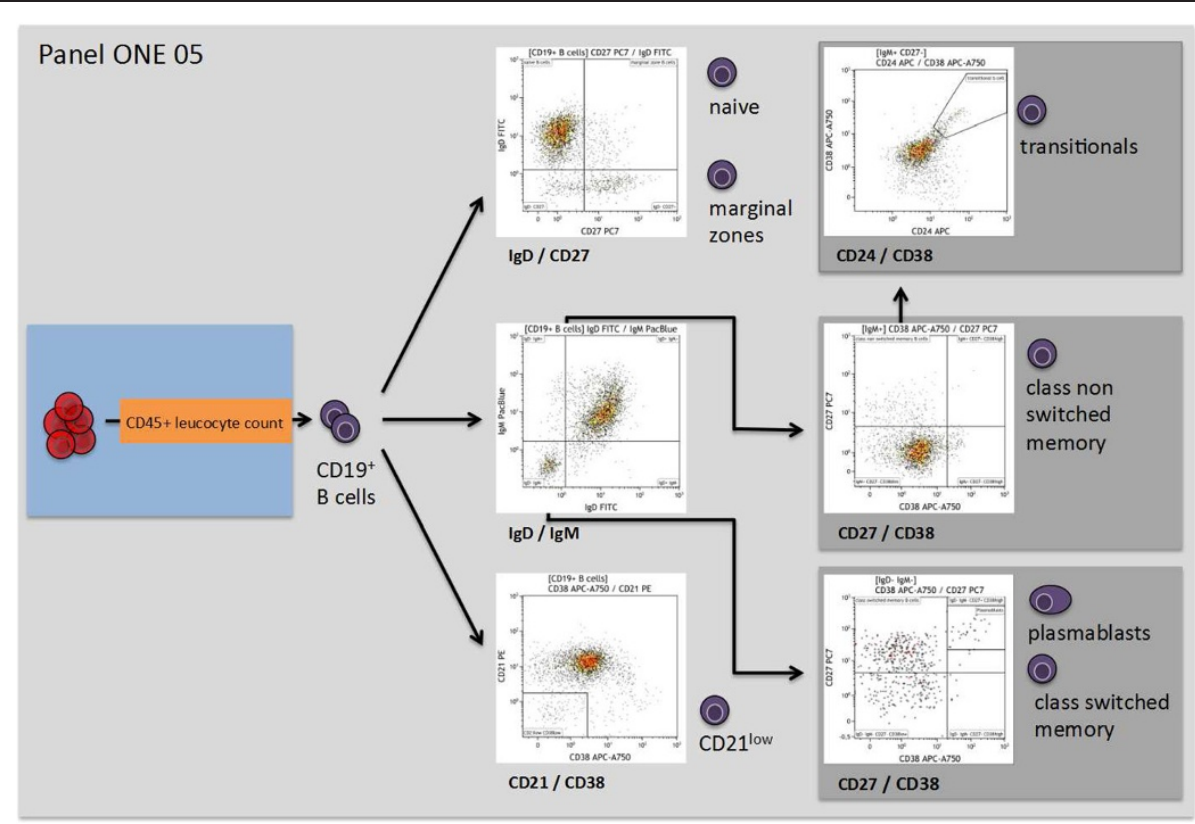

Figure 6 Overview of the gating strategy for panel ONE 05: B cell subsets. Identification of B cell subsets was based on previously published classifications [36,37]. The data file of the stained lysed (EDTA spiked) whole blood (WB) was analyzed as follows: exclusion of non-single events and gating of $\mathrm{CD}_{4} 5^{+}$leukocytes as shown for panel ONE 01 (Figure 2); gating of CD19+ B cells (anti-CD19 versus sideward scatter); gating of CD21 low B cells (antiCD38 versus anti-CD21); gating of $\operatorname{lgD} \lg M^{-}$and $\operatorname{lgM}^{+} B$ cells (anti-lgD versus anti-lgM). Pre-gated $\operatorname{lgD} \operatorname{lgM}^{-} B$ cells were further used to identify plasmablasts $\left(\mathrm{CD} 27^{+} \mathrm{CD} 38^{\text {high }}\right)$ and class-switched memory B cells $\left(\mathrm{CD} 27^{+} \mathrm{CD} 38^{\text {low })}\right.$, pre-gated lgM $\mathrm{M}^{+} \mathrm{B}$ cells were used to identify of class non-switched memory B cells $\left(\mathrm{CD} 27^{+} \mathrm{CD} 38^{\text {lom }}\right.$ ), and the pre-gated IgM+CD27 B cells were used to identify transitional B cells $\left(C D 24^{+} \mathrm{CD} 28^{\text {high }}\right)$. WB, whole blood.

Precision profile was used to evaluate the lower limits of the measuring range. We will refer to this limit as the lower limit of quantitation (LoQ) [43]. LoQ was the lowest limit of the measuring range where the leukocyte subpopulation was determined within an acceptable level of imprecision. We chose to represent imprecision by different target $\mathrm{CV}$ values, as shown in Figure 8.
The solution for estimating LoQ from the precision profile using different target $\mathrm{CV}$ values (Target_CV) was as follows:

$$
L o Q=\exp \left[\frac{\operatorname{Ln}\left(\frac{T \arg e t_{-} C V}{a}\right)}{b}\right]
$$

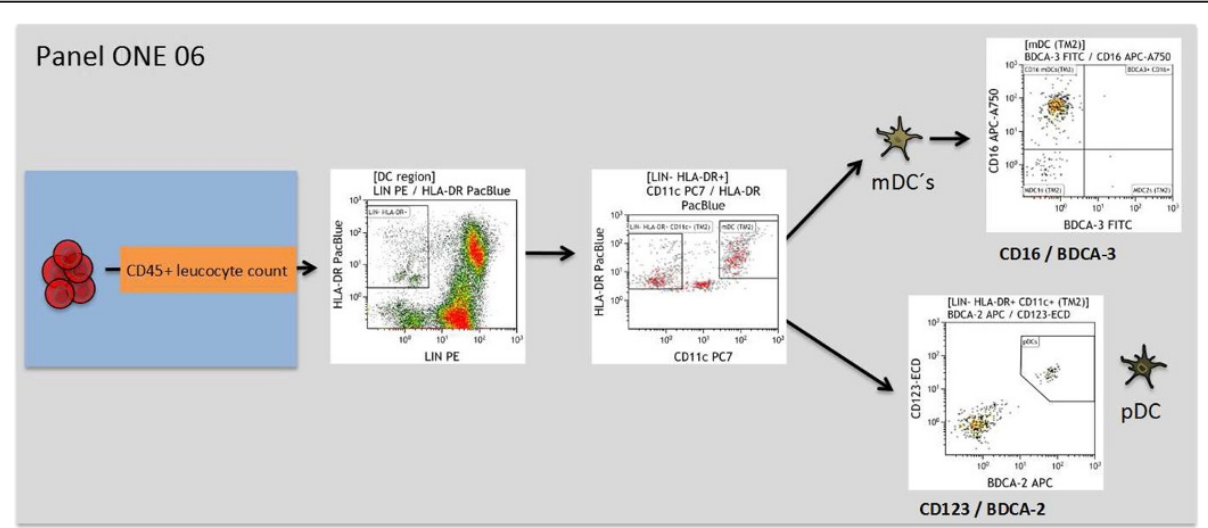

Figure 7 Overview of the gating strategy for panel ONE 06: dendritic cell (DC) subsets. DCs and their subpopulations were identified, as previously reported [38-41]. The data file of the stained lysed (EDTA spiked) whole blood (WB) was analyzed as follows: exclusion of non-single events and gating of CD45 leukocytes as shown for panel ONE 01 (Figure 2); gating of lineage (LIN; anti-CD3, anti-CD14, anti-CD19, anti-CD20, anti-CD56) negative HLA-DR ${ }^{+}$cells, identification of LINHLA-DR ${ }^{+}$CD11 $c^{+}$myeloid DCs (mDCs), and LINHLA-DR ${ }^{+} C D 11 c^{-}$cells (anti-CD11c versus anti-HLA-DR). Pre-gated mDCs were used to identify $C D 16^{+}, \mathrm{mDC1}$, and BDCA3 ${ }^{+} \mathrm{mDC}$ subsets, and pre-gated LIN HLA-DR ${ }^{+} \mathrm{CD} 11 \mathrm{C}^{-}$cells were used to identify plasmacytoid DCs (CD123+BDCA2 ${ }^{+}$). DC, dendritic cell; $\mathrm{mDC}$, myeloid dendritic cell; LIN, lineage; WB, whole blood. 

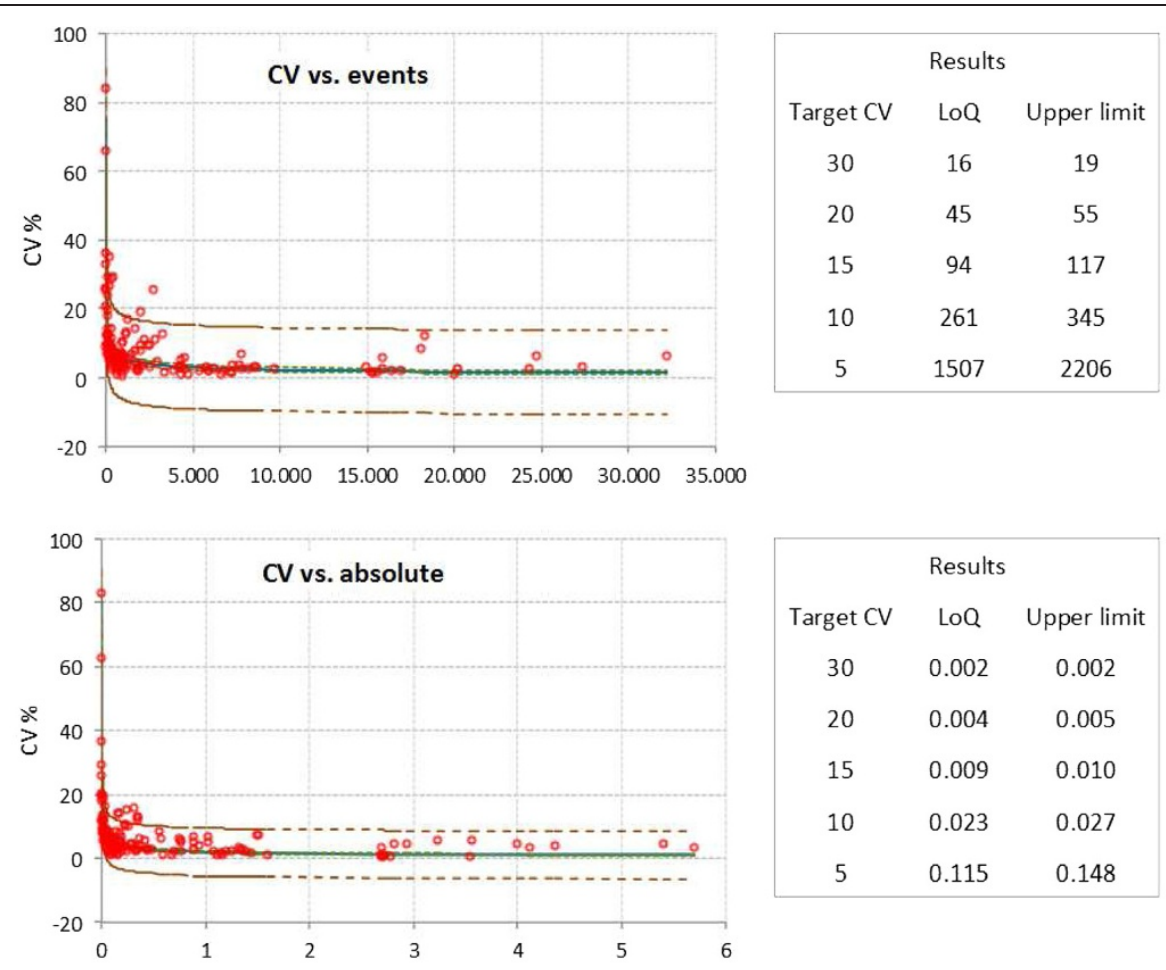

\begin{tabular}{|ccc|}
\hline \multicolumn{3}{|c|}{ Results } \\
Target CV & LoQ & Upper limit \\
30 & 0.002 & 0.002 \\
20 & 0.004 & 0.005 \\
15 & 0.009 & 0.010 \\
10 & 0.023 & 0.027 \\
5 & 0.115 & 0.148 \\
\hline
\end{tabular}

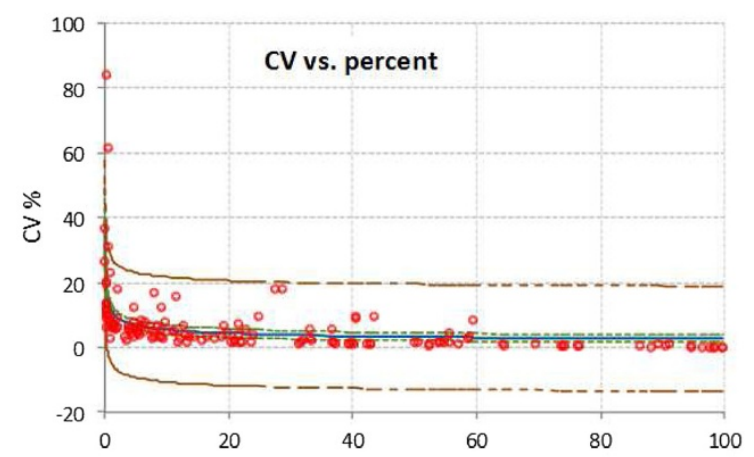

\begin{tabular}{|ccc|}
\hline \multicolumn{3}{|c|}{ Results } \\
Target CV & LoQ & Upper limit \\
30 & 0.05 & 0.08 \\
20 & 0.18 & 0.27 \\
15 & 0.44 & 0.65 \\
10 & 1.56 & 2.42 \\
5 & 13.61 & 25.69 \\
\hline
\end{tabular}

$\mathrm{O} \% \mathrm{CV}$ - profile - - confidence bands - - confidence bands of data

Figure 8 Single CV values of all cell subsets tested within intra-assays (whole blood (WB) material from two healthy individuals; $\mathbf{7 1}$ single subsets $=\mathbf{1 4 2}$ data points). CV values include five replicates assayed in parallel. Shown are the function, regression, and $\mathbf{9 5 \%}$ confidence interval of the CV versus counted events, CV versus calculated absolute cell number of the gated subpopulations, and CV versus percentage of the gated subpopulation. Also shown are the calculated lower limits of quantitation (LoQ) and the upper LoQ for a given CV. CV, coefficient of variation; LoQ, limit of quantitation; WB, whole blood.

Taylor's series approximation was used to calculate standard error of LoQ. The upper confidence limits were based on the standard error of LoQ and 95\% confidence interval.

\section{Results}

\section{Panel setup and optimization of staining procedure}

The immune response towards allogeneic transplants involves activation and alterations of leukocytes from both the adaptive and the innate immune system [44-48]. Furthermore, comparative analysis of peripheral blood from operationally tolerant and non-tolerant patients has revealed differences in the composition of, for example, regulatory $\mathrm{T}$ cells, memory B cells, but also $\gamma \delta \mathrm{T}$ cells and NK cells [44,49-52]. Thus, we designed six 7- to 9-color flow panels that allow the capture of frequencies, numbers, differentiation, and activation of nearly all described blood leukocyte subsets (see also Figures 2, 3, 4, 5, 6, and 7, and Additional file 1: Figure S1).

To avoid alterations in leukocyte composition and activation, which can occur upon PBMC isolation, and to ensure comparability between centers, staining was 
performed on WB and the staining procedure was kept as simple as possible. This resulted in a single protocol for surface staining and for setting compensation of five of the six staining panels, as outlined in the Methods section.

Examination of B cell subpopulations in panel ONE 05 required that free immunoglobulins in the plasma were removed by washing prior to staining of surface $\operatorname{IgD}$ and IgM. This washing step was combined with pre-staining erythrocyte lysis, which also ensured the enrichment and subsequent staining of low abundance cells such as plasmablasts and transitional B cells. The pre-washing step was necessary as free immunoglobulins in the serum particularly affect surface staining of IgM and IgD, as shown in Additional file 4: Figure S2.

The gated defining negative and positive leukocyte subpopulations for each surface marker were set using color density bi-exponential displays, as also recommended by others [26], except when displaying the cells according to their scatter signals. All together, the staining procedures described here and the presented gating strategy (Figures 2, 3, 4, 5, 6, and 7) allowed for good discrimination of all target leukocyte populations using fresh WB material of healthy individuals.

\section{Precision, robustness, and biological variability}

To evaluate the precision of the test system, intra-assay, inter-assay, and inter-operator tests were performed, and the CVs of percent positive cells and absolute cell counts were calculated. A fixed template for gating on leukocyte subsets and defining true positive subpopulations was used to improve standardization of the analysis system. The CV for the intra-assay test with five assay replicates per WB sample allowed an analysis of the tube-to-tube consistency. The replicate tube was assayed in parallel, and the intra-assay $\mathrm{CV}$ was calculated from the relative values, the counted event numbers, and the absolute cell number for each population (Figure 9).

At least 142 single CVs of 71 subpopulations were included in the analysis (Figures 8 and 9). Comparing the relative counts for the gated populations (that is, percentages), only three cell populations from the 71 total populations exceeded a CV of $20 \%$. Furthermore, only 12 cell populations had a CV of greater than $10 \%$. Similar results were obtained when calculating the $\mathrm{CV}$ for absolute cell numbers. Five populations showed a CV above $20 \%$, and 20 populations a $\mathrm{CV}$ above $10 \%$. CV values calculated for the percentages of all lineage markers (CD45, CD3, CD4, CD8, CD19, CD56) were below $4 \%$, except for the monocytes, which had a mean CV of $7.5 \%$.

The inter-operator $\mathrm{CV}$ was calculated as outlined for the intra-assay test. Mean CVs were compared to the calculations of the intra-assay test; more than $80 \%$ of the CVs varied by less than 1\% (Figure 10). Considerable increases in inter-operator CVs, as compared to intraassay CVs, were observed for the monocytes and their subpopulations, which was independent of the size of the populations or the number of counted events. To test whether immunosuppressive therapy may impact variability of leukocyte subset identification, we performed inter-operator tests on samples collected from transplant patients on three different days, which were stained by three different operators. Importantly, all specified leukocyte subpopulations could be identified in the blood of immunosuppressed transplant patients. Furthermore, the determined variability of individual subsets was nearly identical as compared to values detected by staining blood collected from healthy volunteers (Additional file 5: Figure S3).

Inter-assay variability was determined by staining cells from four healthy individuals on three consecutive days. The mean CVs of the inter-assay test were up to $12 \%$ greater than the CVs of the intra-assay for the majority of cell populations (Figure 9). This is consistent with previous observations that the biological variability in a WB test with fresh blood donations over several consecutive days is significantly greater than classical interassay variability, at which the same sample is stained on three consecutive days [46]. For some leukocyte subsets such as $\mathrm{CD} 4^{+} \mathrm{CD} 28^{-} \mathrm{T}$ cells, plasmablasts, or MDC2 DCs, higher CVs (up to $30 \%$ ) were observed due to the small population size (lower event counts). Only the CV values for the monocyte subpopulations increased similarly to the inter-operator test, regardless of population size. Stabilizing blood collection devices (for example, Cyto-Chex blood collection tubes) could not be used to reduce inter-assay variability, as they affect expression of some surface markers such as CD62L and CCR7 on T cells, and particularly IgM on B cells (Additional file 6: Figure S4). Therefore, inter-assay data was excluded from the precision and LoQ estimations, as described later on (Figure 8).

\section{Stability of collected material and stained samples}

The variability as a result of blood specimen age prior to staining was estimated by the age-of-blood test. The variability for a change from baseline ( 0 hours) of 4 hours ranged up to $65 \%$ for some gated populations, compared to immediate staining after blood collection. Again, variability was highest in low-abundant cell populations such as plasmablasts (CV of $65 \%$ ). Thus the change from baseline variability negatively correlates with the WB frequency or absolute cell count.

Within the 4-hour window, a small amount of variability was observed for all lineage markers and $\mathrm{T}$ cell subsets (up to $10 \%$ ), whereas the variability for the monocyte, B cell, and DC subpopulations increased by up to more than $20 \%$. Performing the staining at 24 hours after blood 


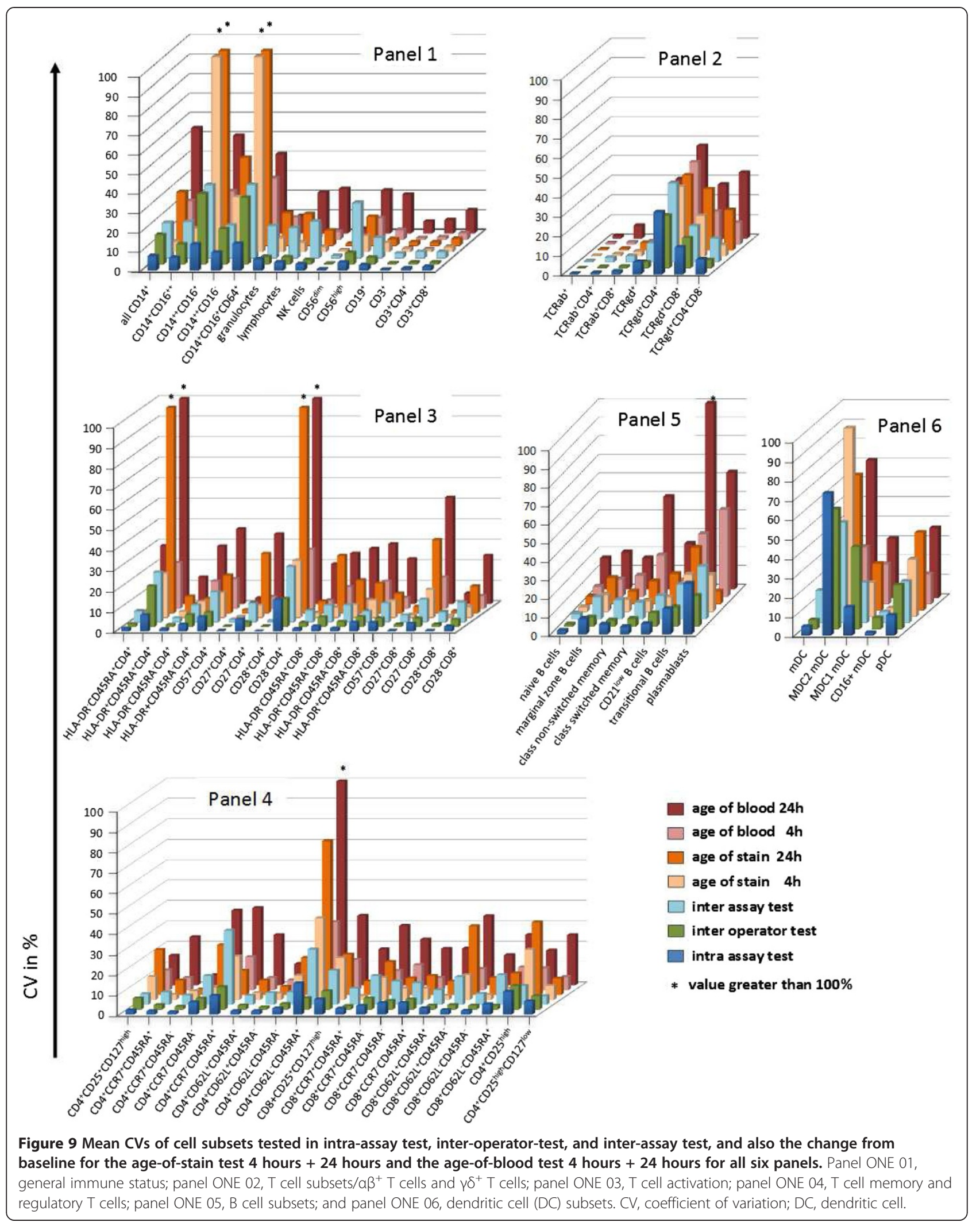




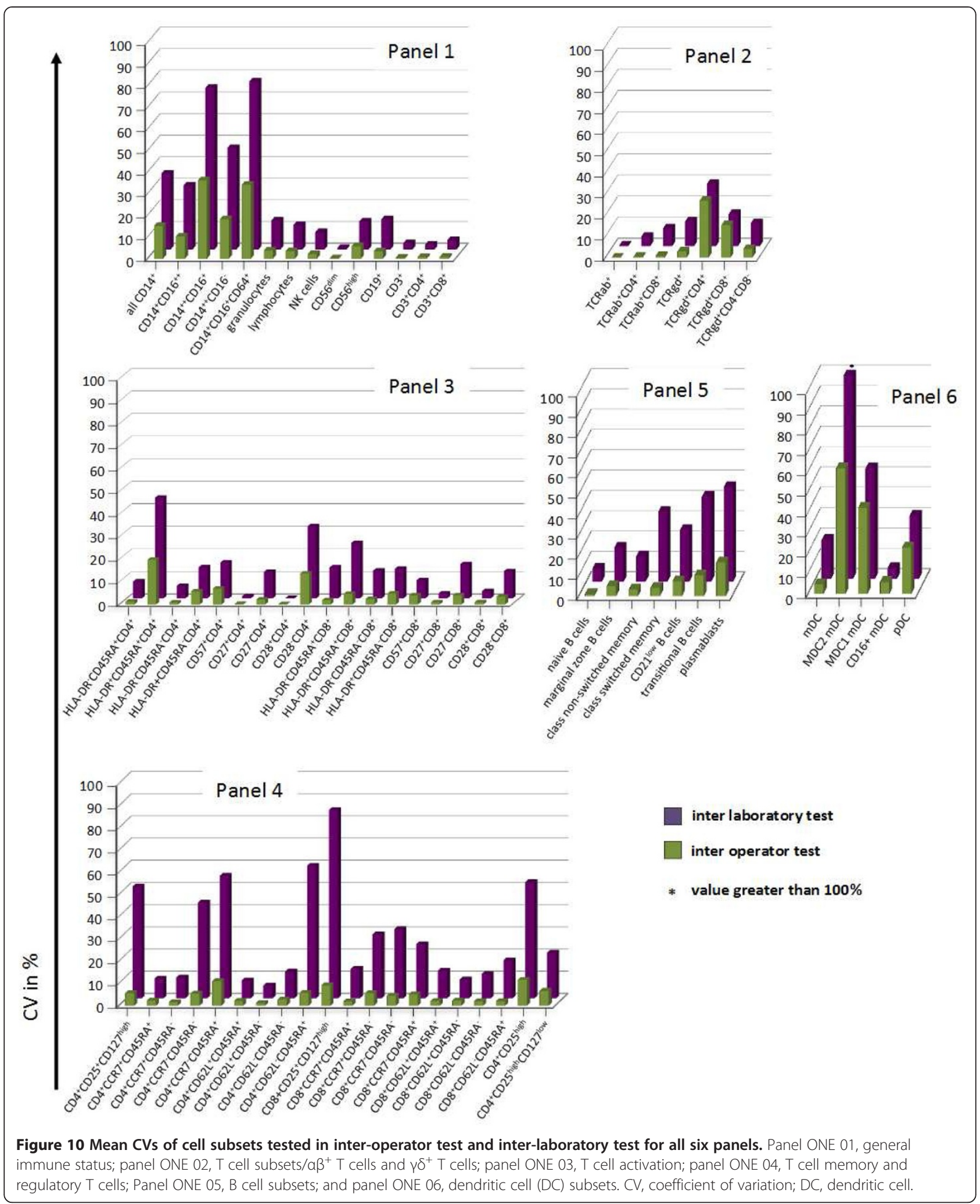

collection increased the variability for all subsets, especially for the aforementioned critical populations, which in some cases reached excessive values of up to $200 \%$. Thus, staining of WB samples within 4 hours of collection is of utmost importance for reliable results. 
Next, we determined the variability in defining the leukocyte subsets following a time delay of 4 hours between sample staining and measurement. We observed very little variability with small CVs for most parameters, which again correlated with the number of counted events and percentages of gated populations (Figure 9). Variability of infrequent populations increased slightly following a time delay of 24 hours between staining and measurement. Significant differences were found again only for monocyte subpopulations.

\section{Reproducibility test by inter-site comparison}

To evaluate the reproducibility between participating sites, inter-site comparisons were performed. Different time points for the first enrollment of patients at different ONE Study sites meant that this test was performed several times, but always included different participating sites. Here we show the results of two inter-site comparisons between three laboratories within Europe for the first comparison, and between five laboratories in Europe and one in the USA for the second comparison. The second inter-laboratory comparison posed a particular challenge due to the long shipment time of WB samples from Berlin to San Francisco. The specimen age stability data described above meant that there was an expected impact due to the age of the blood specimen. Assays were performed simultaneously according to the standard SOPs at all sites. Due to shipment, staining was started 24 hours after blood collection for the first intersite comparison and 30 hours after blood collection in case of the second test. Overall CVs below 15\% were obtained for $66 \%$ of the parameters (Figure 10). Similar to the other variability tests, significant increases were observed in the CVs for the monocyte subpopulations, and rather infrequent $\mathrm{B}$ cell (transitional $\mathrm{B}$ cells and plasmablasts), $\mathrm{DC}$, and $\mathrm{CD} 4{ }^{+} \mathrm{CD} 25^{\text {high }} \mathrm{T}$ cell populations.

The original data of all validation tests are given within Additional file 7: Figure S5.

\section{Defining limits of quantitation (LoQ)}

Since the biological variability of blood collected on three consecutive days, as it was done for the inter-assay variability test, can be quite high and does not correspond to a classical inter-assay test, the results of the intra-assay evaluation were used to calculate the LoQ and 95\% confidence interval (see Methods section).

When plotting CVs versus the percentages, absolute numbers and counted events for each leukocyte subpopulation revealed increasing $\mathrm{CVs}$ as a function of all three parameters (Figure 8). We detected increased CV values with a decreased number of counted events, absolute cell numbers, and acquired numbers of cells in leukocyte subpopulations. Therefore, it is impossible to define the same cut-off value for the CV of all leukocyte subsets. We rather calculated the lower (LoQ) and upper limits of absolute cell counts, frequencies, or acquired events for a given target $\mathrm{CV}$ using the power function described within the Methods (Figure 8). Accordingly, a leukocyte subpopulation occurring with a frequency of $0.5 \%$ per all $\mathrm{CD} 45^{+}$leukocytes can be identified and quantified assuming a CV of up to $15 \%$. All subpopulations met these LoQ criteria except for two monocyte subpopulations $\left(\mathrm{CD} 16^{+} \mathrm{CD} 64^{+}\right.$and $\left.\mathrm{CD} 14^{\text {high }} \mathrm{CD} 16^{+}\right)$, and the $\mathrm{CD} 4^{+} \mathrm{CD} 25^{\text {high }}$ subpopulation. This function of $\mathrm{CVs}$ will also ensure a reliable definition of significant differences observed for a subset between patient populations. Changes in leukocyte subsets between patient populations will need to be equal or higher to the corresponding CV calculated by the function.

\section{Discussion}

As the precision of flow cytometric profiling of WB samples is impacted by many variables, standardization becomes crucial for use when immune monitoring within clinical trials. For the immune monitoring of transplant patients within the ONE Study, we defined six flow cytometry panels that are being used to stain WB samples locally at all participating clinical sites, followed by a central gating and leukocyte subset analysis, as previously recommended $[17,19,26,53]$. The results of the performance evaluation of the panels described here demonstrate highly reproducible SOPs that are applicable in general for use in multicenter clinical trials.

We detected low variability in leukocyte subset frequency and absolute counts between different local laboratories for the majority of the leukocyte cell subpopulations, especially for the $\mathrm{T}$ cell subsets. Although more variable, monocyte subsets and certain subsets of DCs and B cells show acceptable variability of up to $30 \%$. While the affected DC and B cell subsets encompass small populations with low absolute cell counts that contribute to higher variability, monocyte subsets show higher variability independent of population size or absolute cell count. Nonetheless, we are now able to define limits for statistically significant relative and absolute changes between patient cohorts for the leukocyte subsets as defined by intra-assay (Figures 8 and 9) and inter-operator variability, which is highly dependent on the subset abundance, as previously reported [53]. Applying the developed function for target $\mathrm{CVs}$ in relation to, for example, cell frequency, observed differences for a leukocyte subset between two patient populations can only reach significance if those differences are higher than the calculated CV. Thus, a leukocyte population occurring on average at a frequency of $0.5 \%$ can only change significantly if an increase or decrease by at least $15 \%$ is detected. 
Importantly, the acceptable variability in this study was not only achieved when staining samples collected from healthy volunteers, but also with samples from kidney transplant recipients on immunosuppressive therapy. This clearly shows the feasibility of the staining protocols for use in multicenter clinical trials enrolling kidney transplant patients.

There are many possible reasons for exceptional behavior of monocytes and their subsets, and difficulties in standardized enumeration of monocytes have been reported previously $[54,55]$. Due to their inherent nature, monocytes tend to adhere to plastic surfaces, which may become more relevant with a longer storage time. However, while this can explain the variability observed due to specimen age and inter-site comparisons with aged (24- and 30-hour) blood, it does not explain the increased variability detected within inter-assay and interoperator comparisons.

Considering all factors, including the feasibility of a minimal time delay between blood collection/processing, and our observed alterations in determined subset frequency and count, we defined a time window of 4 hours for WB staining. By doing so, an acceptable variability of below $30 \%$ is achievable for most cell populations, except for infrequent populations such as plasma blasts or certain monocyte subpopulations.

It has been reported by several groups that perhaps the largest single contributor to variability in flow cytometry is the difference in gating the target leukocyte populations [17-19,56]. To control for such alteration, a centralized gating and target definition strategy was chosen. This strategy corresponds to the 'mixed model' reported by Maecker et al. [17], in which samples are supposed to be obtained, processed, and acquired at local sites through the use of strict SOPs, with a central laboratory performing the analysis of acquired flow cytometry files.

To avoid misclassification of negative and positive leukocyte subsets, and thus misinterpretation of the results, which can easily happen within multicenter clinical trials, we based the gating strategy nearly completely on color density bi-exponential displays. Furthermore, following panel establishment and optimization, a template analysis protocol for the gating strategy was created for each panel, approved by all sites, and subsequently used for the analysis of all files. Only in the case of the 24-hour age-of-blood and inter-site comparisons did the pre-defined gates have to be slightly modified. This was due to alterations in forward and side scatter positions of individual leukocyte subsets upon prolonged WB storage (24 and 30 hours in case of inter-site comparisons). During the trial, specimen age will be strictly controlled to less than 4 hours before staining, so this gating change will not be needed and will not impact patient sample analysis.
In summary, our defined flow cytometry panels allow enumeration of the abundance and activation of a large number of leukocyte subsets with a high precision across multiple international sites. Using this standardized strategy of leukocyte profiling to identify changes in leukocyte subsets, we propose that it will be feasible to detect effects of immunomodulatory treatments within and between multicenter clinical trials. Therefore, this operating procedure will not only be useful in the context of the ONE Study trials, it could also be applied to other clinical trials where sensitive immune monitoring provides valuable information. Equally important, the sharing of procedures and protocols for flow cytometry will allow for more reliable comparisons of immunological effects between these different clinical trials.

\section{Additional files}

Additional file 1: Figure S1. Panel matrix for flow cytometry-based immune monitoring within the ONE Study. Listed are all antibodies with clone ID and fluorochrome conjugate.

Additional file 2: Method S6. Method describing the standard operating procedure for staining of whole blood leukocytes with panel ONE 01, 02, 03, 04, 06.

Additional file 3: Method S7. Describing the standard operating procedure for staining of whole blood leukocytes with panel ONE 05.

Additional file 4: Figure S2. Exemplary dot plots for surface IgM staining on CD19 ${ }^{+}$B cells comparing whole blood (WB) staining with and without prior removal of free plasma immunoglobulins by an ammonium chloride-based lyse/wash step.

Additional file 5: Figure S3. Mean CVs of cell subsets were calculated in inter-operator test on samples collected from transplant patients 3 to 6 months after kidney transplantation for all six panels: panel ONE 01, general immune status; panel ONE 02, T cell subsets/a $\beta^{+} T$ cells and $\gamma \delta^{+}$ T-cells; panel ONE 03, T cell activation; panel ONE 04, T cell memory and regulatory T cells; panel ONE 05, B cell subsets; and panel ONE 06, dendritic cell (DC) subsets.

Additional file 6: Figure S4. Comparative analysis of leukocyte staining of whole blood (WB) samples collected into EDTA or Cyto-Chex tubes. Shown are dot plots of CCR7 versus CD45RA, and CD62L versus CD45RA staining for $C D 4^{+} T$ cells using the same gating strategy as described in Figure 5. Additionally lgM versus IgD staining of CD19+ $\mathrm{B}$ cells is displayed applying the same gating strategy as described in Figure 6.

Additional file 7: Figure S5. Shown are all results for the validation of the flow cytometry immune monitoring for the ONE Study, including all single CVs and mean CVs, respectively, and all changes from baseline and mean changes from baseline for all test assays.

\section{Abbreviations}

CV: Coefficient of variation; DC: Dendritic cell;

EDTA: Ethylenediaminetetraacetic acid; FCS: Fetal calf serum; HLDA: Human leukocyte differentiation antigen; IgD: Immunoglobulin $D_{\text {; }}$

IgM: Immunoglobulin M; LoQ: Limit of quantitation; mDC: Myeloid dendritic cell; MFI: Mean fluorescence intensity; Mreg: Regulatory macrophage; NK: Natural killer; nTreg: Naturally occurring regulatory T cell; PBMC: Peripheral blood mononuclear cell; PBS: Phosphate buffered saline; SOP: Standard operating procedure; SSC: Sideward scatter; Tr1: Type 1 regulatory T; WB: Whole blood.

\section{Competing interests}

Reagents and Navios flow cytometers for this study were provided by Beckman Coulter. MK, RM, TM, and MR are employees of Beckman Coulter. 


\section{Authors' contributions}

$M S, T M, M K, M R, E K G, J H, C M, H D V$, and BS participated in research design. $M S, R M$, and BS participated in writing of the manuscript. MS, TM, MK, KV, SS, and AHK participated in the performance of the research. MS, RM, and BS participated in the data analysis. All authors read and approved the final manuscript.

\section{Acknowledgements}

The following additional principal investigators were part of the ONE Study flow cytometry group, involved in performing, for example, the inter-site comparisons: Andrew Bushell, Kathryn Wood, Maria Hernandez-Fuentes, Cristiano Scotta, Karim Lee, Qizhi Tang, Regis Josien, Cecile Braudeau, Manuela Battaglia, Eleonora Tresoldi, and Sharon Germana. The ONE Study is funded by the European Seventh Framework Program (grant 260687) of the European Commission.

\section{Author details}

'Institute of Medical Immunology, Charité - Universitätsmedizin Berlin, Augustenburger Platz 1, Berlin 13353, Germany. ${ }^{2}$ Global Assay and Applications Development, Beckman Coulter, Inc, 130 Av. De Lattre de Tassigny, B.P. 177, Marseille Cedex 9, France. ${ }^{3}$ Global Assay and Applications Development, Beckman Coulter, Inc, 11800 SW 147th Ave, Miami, FL 33196, USA. ${ }^{4}$ Department of Surgery, University Hospital Regensburg, University of Regensburg, Regensburg, Germany. ${ }^{5}$ Berlin-Brandenburg Center for Regenerative Therapies (BCRT), Charité - Universitätsmedizin Berlin, Berlin, Germany.

Received: 12 June 2013 Accepted: 24 September 2013 Published: 25 October 2013

\section{References}

1. Battaglia M, Roncarolo MG: Immune intervention with T regulatory cells: past lessons and future perspectives for type 1 diabetes. Semin Immunol 2011, 23(3):182-194.

2. Broichhausen C, Riquelme P, Geissler EK, Hutchinson JA: Regulatory macrophages as therapeutic targets and therapeutic agents in solid organ transplantation. Curr Opin Organ Trans 2012, 17(4):332-342.

3. Ezzelarab M, Thomson AW: Tolerogenic dendritic cells and their role in transplantation. Semin Immunol 2011, 23(4):252-263.

4. Schliesser U, Streitz M, Sawitzki B: Tregs: application for solid-organ transplantation. Curr Opinion Organ Trans 2012, 17(1):34-41.

5. Brunstein CG, Miller JS, Cao Q, McKenna DH, Hippen KL, Curtsinger J, Defor T, Levine BL, June CH, Rubinstein P, McGlave PB, Blazar BR, Wagner JE: Infusion of ex vivo expanded T regulatory cells in adults transplanted with umbilical cord blood: safety profile and detection kinetics. Blood 2011, 117(3):1061-1070.

6. Feng G, Nadig SN, Bäckdahl L, Beck S, Francis RS, Schiopu A, Whatcott A, Wood KJ, Bushell A: Functional regulatory T cells produced by inhibiting cyclic nucleotide phosphodiesterase type 3 prevent allograft rejection. Sci Transl Med 2011, 3(83):83.

7. Issa F, Hester J, Goto R, Nadig SN, Goodacre TE, Wood K: Ex vivo-expanded human regulatory $T$ cells prevent the rejection of skin allografts in a humanized mouse model. Transplantation 2010, 90(12):1321-1327.

8. Schmetterer KG, Neunkirchner A, Pickl WF: Naturally occurring regulatory $T$ cells: markers, mechanisms, and manipulation. FASEB J 2012, 26(6):2253-2276

9. Gregori S, Goudy KS, Roncarolo MG: The cellular and molecular mechanisms of immuno-suppression by human type 1 regulatory $T$ cells. Front Immunol 2012, 3:30.

10. Gregori S, Roncarolo MG, Bacchetta R: Methods for in vitro generation of human type 1 regulatory T cells. Method Mol Biol 2011, 677:31-46.

11. Roncarolo MG, Gregori S, Lucarelli B, Ciceri F, Bacchetta R: Clinical tolerance in allogeneic hematopoietic stem cell transplantation. Immunol Rev 2011, 241(1):145-163.

12. Hutchinson JA, Riquelme P, Geissler EK: Human regulatory macrophages as a cell-based medicinal product. Curr Opini Organ Trans 2012, 17(1):48-54

13. Hutchinson JA, Riquelme P, Sawitzki B, Tomiuk S, Miqueu P, Zuhayra M, Oberg HH, Pascher A, Lützen U, Janssen U, Broichhausen C, Renders L, Thaiss F, Scheuermann E, Henze E, Volk HD, Chatenoud L, Lechler RI, Wood KJ, Kabelitz D, Schlitt HJ, Geissler EK, Fändrich F: Cutting edge: immunological consequences and trafficking of human regulatory macrophages administered to renal transplant recipients. J Immuno 2011, 187(5):2072-2078.

14. Kalantari T, Kamali-Sarvestani E, Ciric B, Karimi MH, Kalantari M, Faridar A, $\mathrm{Xu} \mathrm{H}$, Rostami A: Generation of immunogenic and tolerogenic clinical-grade dendritic cells. Immunol Res 2011, 51(2-3):153-160.

15. Moreau A, Varey E, Bériou G, Hill M, Bouchet-Delbos L, Segovia M, Cuturi MC: Tolerogenic dendritic cells and negative vaccination in transplantation: from rodents to clinical trials. Front Immunol 2012, 3:218.

16. Moreau A, Varey E, Bouchet-Delbos L, Cuturi MC: Cell therapy using tolerogenic dendritic cells in transplantation. Trans Res 2012, 1(1):13.

17. Maecker HT, McCoy JP Jr, Human Immunophenotyping Consortium FOCIS, Amos M, Elliott J, Gaigalas A, Wang L, Aranda R, Banchereau J, Boshoff C, Braun J, Korin Y, Reed E, Cho J, Hafler D, Davis M, Fathman CG, Robinson W, Denny T, Weinhold K, Desai B, Diamond B, Gregersen P, Di Meglio P, Nestle FO, Peakman M, Villanova F, Ferbas J, Field E, Kantor A, et al: A model for harmonizing flow cytometry in clinical trials. Nat Immunol 2010, 11(11):975-978.

18. Kalina T, Flores-Montero J, van der Velden VH, Martin-Ayuso M, Böttcher S, Ritgen M, Almeida J, Lhermitte L, Asnafi V, Mendonça A, de Tute R, Cullen M, Sedek L, Vidriales MB, Pérez JJ, te Marvelde JG, Mejstrikova E, Hrusak O, Szczepański T, van Dongen JJ, Orfao A, EuroFlow Consortium (EU-FP6, LSHB-CT-2006-018708): EuroFlow standardization of flow cytometer instrument settings and immunophenotyping protocols. Leukemia 2012, 26(9):1986-2010.

19. Maecker HT, McCoy JP, Nussenblatt R: Standardizing immunophenotyping for the human immunology project. Nat Rev Immunol 2012, 12(3):191-200.

20. Mahnke $Y$, Chattopadhyay $P$, Roederer M: Publication of optimized multicolor immunofluorescence panels. Cytometry A 2010, 77(9):814-818.

21. Arjona A, Sarkar DK: Evidence supporting a circadian control of natural killer cell function. Brain Behav Immun 2006, 20(5):469-476.

22. Bollinger T, Bollinger A, Skrum L, Dimitrov S, Lange T, Solbach W: Sleep-dependent activity of T cells and regulatory T cells. Clini Exp Immunol 2009, 155(2):231-238.

23. Levi FA, Canon C, Touitou Y, Reinberg A, Mathe G: Seasonal modulation of the circadian time structure of circulating $T$ and natural killer lymphocyte subsets from healthy subjects. J Clini Invest 1988 81(2):407-413

24. Shantsila E, Tapp LD, Wrigley BJ, Montoro-Garcia S, Ghattas A, Jaipersad A, Lip GY: The effects of exercise and diurnal variation on monocyte subsets and monocyte-platelet aggregates. Eur J Clin Invest 2012. 42(8):832-839.

25. Maecker HT, Frey T, Nomura LE, Trotter J: Selecting fluorochrome conjugates for maximum sensitivity. Cytometry A 2004, 62(2):169-173.

26. Herzenberg LA, Tung J, Moore WA, Herzenberg LA, Parks DR: Interpreting flow cytometry data: a guide for the perplexed. Nat Immunol 2006, 7(7):681-685.

27. Betjes MG, Huisman M, Weimar W, Litjens NH: Expansion of cytolytic CD4 + CD28- T cells in end-stage renal disease. Kidney Int 2008, 74(6):760-767.

28. Gilani SR, Vuga LJ, Lindell KO, Gibson KF, Xue J, Kaminski N, Valentine VG, Lindsay EK, George MP, Steele C, Duncan SR: CD28 down-regulation on circulating CD4 T-cells is associated with poor prognoses of patients with idiopathic pulmonary fibrosis. Plos One 2010, 5(1):e8959.

29. Lenkei $R$, Andersson B: High correlations of anti-CMV titers with lymphocyte activation status and CD57 antibody-binding capacity as estimated with three-color, quantitative flow cytometry in blood donors. Clin Immunol Immunopathol 1995, 77(2):131-138.

30. Mack DG, Lanham AM, Palmer BE, Maier LA, Fontenot AP: CD27 expression on CD4+ T cells differentiates effector from regulatory $T$ cell subsets in the lung. J Immunol 2009, 182(11):7317-7324.

31. Pinto-Medel MJ, García-León JA, Oliver-Martos B, López-Gómez C, Luque G, Arnáiz-Urrutia C, Orpez T, Marín-Bañasco C, Fernández O, Leyva L: The CD4+ T-cell subset lacking expression of the CD28 costimulatory molecule is expanded and shows a higher activation state in multiple sclerosis. J Neuroimmunol 2012, 243(1-2):1-11.

32. Tarazona R, DelaRosa O, Alonso C, Ostos B, Espejo J, Peña J, Solana R: Increased expression of NK cell markers on T lymphocytes in aging and chronic activation of the immune system reflects the accumulation of effector/senescent T cells. Mech Ageing Dev 2000, 121(1-3):77-88. 
33. Gerlach UA, Vogt K, Schlickeiser S, Meisel C, Streitz M, Kunkel D, Appelt C, Ahrlich S, Lachmann N, Neuhaus P, Pascher A, Sawitzki B: Elevation of CD4+ differentiated memory T cells is associated with acute cellular and antibody-mediated rejection after liver transplantation. Transplantation 2013, 95:1512-1520.

34. Sallusto F, Langenkamp A, Geginat J, Lanzavecchia A: Functional subsets of memory T cells identified by CCR7 expression. Curr Topics Microbiol Immunol 2000, 251:167-171.

35. Venken K, Hellings N, Broekmans T, Hensen K, Rummens JL, Stinissen P: Natural naive CD4 + CD25 + CD127low regulatory T cell (Treg) development and function are disturbed in multiple sclerosis patients: recovery of memory Treg homeostasis during disease progression. J Immunol 2008, 180(9):6411-6420.

36. Rehnberg M, Amu S, Tarkowski A, Bokarewa MI, Brisslert M: Short- and long-term effects of anti-CD20 treatment on B cell ontogeny in bone marrow of patients with rheumatoid arthritis. Arthritis Res Ther 2009, 11(4):R123.

37. Wehr C, Kivioja T, Schmitt C, Ferry B, Witte T, Eren E, Vlkova M, Hernandez M, Detkova D, Bos PR, Poerksen G, von Bernuth H, Baumann U, Goldacker S, Gutenberger S, Schlesier M, Bergeron-vander Cruyssen F, Le Garff M, Debré P, Jacobs R, Jones J, Bateman E, Litzman J, van Hagen PM, Plebani A, Schmidt RE, Thon V, Quinti I, Espanol T, Webster AD, et al: The EUROclass trial: defining subgroups in common variable immunodeficiency. Blood 2008, 111(1):77-85.

38. Jongbloed SL, Kassianos AJ, McDonald KJ, Clark GJ, Ju X, Angel CE, Chen CJ, Dunbar PR, Wadley RB, Jeet V, Vulink AJ, Hart DN, Radford KJ: Human CD141+ (BDCA-3) + dendritic cells (DCs) represent a unique myeloid DC subset that cross-presents necrotic cell antigens. J Exp Med 2010, 207(6):1247-1260.

39. Ju X, Clark G, Hart DN: Review of human DC subtypes. Method Mol Biol 2010, 595:3-20.

40. Mittag D, Proietto Al, Loudovaris T, Mannering SI, Vremec D, Shortman K Wu L, Harrison LC: Human dendritic cell subsets from spleen and blood are similar in phenotype and function but modified by donor health status. J Immunol 2011, 186(11):6207-6217.

41. Ziegler-Heitbrock L, Ancuta P, Crowe S, Dalod M, Grau V, Hart DN, Leenen PJ, Liu YJ, MacPherson G, Randolph GJ, Scherberich J, Schmitz J, Shortman K, Sozzani S, Strobl H, Zembala M, Austyn JM, Lutz MB: Nomenclature of monocytes and dendritic cells in blood. Blood 2010, 116(16):e74-e80

42. Sadler WA: Imprecision profiling. Clini Biochem Rev/Aust Assoc Clin Biochem 2008, 29(Suppl 1):S33-S36.

43. International Organization for Standardization (ISO): Capability of Detection Part 1: Terms and definitions. In ISO 11843-1. Geneva: ISO; 1997.

44. Benichou G, Yamada Y, Aoyama A, Madsen JC: Natural killer cells in rejection and tolerance of solid organ allografts. Curr Opin Organ Trans 2011, 16(1):47-53.

45. Benichou G, Yamada Y, Yun SH, Lin C, Fray M, Tocco G: Immune recognition and rejection of allogeneic skin grafts. Immunotherapy 2011, 3(6):757-770.

46. Marcenaro E, Carlomagno S, Pesce S, Moretta A, Sivori S: Bridging innate NK cell functions with adaptive immunity. Adv Exp Med Biol 2011, 780:45-55.

47. Ponticelli C: The mechanisms of acute transplant rejection revisited. J Nephrol 2012, 25(2):150-158.

48. Wood KJ, Goto R: Mechanisms of rejection: current perspectives. Transplantation 2012, 93(1):1-10.

49. Martínez-Llordella M, Puig-Pey I, Orlando G, Ramoni M, Tisone G, Rimola A, Lerut J, Latinne D, Margarit C, Bilbao I, Brouard S, Hernández-Fuentes M, Soulillou JP, Sánchez-Fueyo A: Multiparameter immune profiling of operational tolerance in liver transplantation. Am J Transplant 2007, 7(2):309-319.

50. Puig-Pey I, Bohne F, Benítez C, López M, Martínez-Llordella M, Oppenheimer F, Lozano JJ, González-Abraldes J, Tisone G, Rimola A, Sánchez-Fueyo A: Characterization of gammadelta T cell subsets in organ transplantation. Transplant Int 2010, 23(10):1045-1055.

51. Sagoo P, Perucha E, Sawitzki B, Tomiuk S, Stephens DA, Miqueu P, Chapman S, Craciun L, Sergeant R, Brouard S, Rovis F, Jimenez E, Ballow A, Giral M, Rebollo-Mesa I, Le Moine A, Braudeau C, Hilton R, Gerstmayer B, Bourcier K, Sharif A, Krajewska M, Lord GM, Roberts I, Goldman M, Wood KJ, Newell K, Seyfert-Margolis V, Warrens AN, Janssen U: Development of a cross-platform biomarker signature to detect renal transplant tolerance in humans. J Clin Invest 2010, 120(6):1848-1861.

52. Newell KA, Asare A, Kirk AD, Gisler TD, Bourcier K, Suthanthiran M, Burlingham WJ, Marks WH, Sanz I, Lechler RI, Hernandez-Fuentes MP, Turka LA, Seyfert-Margolis VL, Immune Tolerance Network ST507 Study Group: Identification of a B cell signature associated with renal transplant tolerance in humans. J Clin Invest 2010, 120(6):1836-1847.

53. Maecker HT, Rinfret A, D'Souza P, Darden J, Roig E, Landry C, Hayes P, Birungi J, Anzala O, Garcia M, Harari A, Frank I, Baydo R, Baker M, Holbrook J, Ottinger J, Lamoreaux L, Epling CL, Sinclair E, Suni MA, Punt K, Calarota S, El-Bahi S, Alter G, Maila H, Kuta E, Cox J, Gray C, Altfeld M, Nougarede N, et al: Standardization of cytokine flow cytometry assays. BMC Immunol 2005, 6:13.

54. Bosshart $H$, Heinzelmann M: Spontaneous decrease of CD14 cell surface expression in human peripheral blood monocytes ex vivo. $J$ Immunol Methods 2011, 368(1-2):80-83.

55. Stewart JC, Villasmil ML, Frampton MW: Changes in fluorescence intensity of selected leukocyte surface markers following fixation. Cytometry $A$ 2007, 71(6):379-385.

56. Cunliffe J, Derbyshire N, Keeler S, Coldwell R: An approach to the validation of flow cytometry methods. Pharm Res 2009, 26(12):2551-2557.

\section{doi:10.1186/2047-1440-2-17}

Cite this article as: Streitz et al:: Standardization of whole blood immune phenotype monitoring for clinical trials: panels and methods from the ONE study. Transplantation Research 2013 2:17.

\section{Submit your next manuscript to BioMed Central and take full advantage of:}

- Convenient online submission

- Thorough peer review

- No space constraints or color figure charges

- Immediate publication on acceptance

- Inclusion in PubMed, CAS, Scopus and Google Scholar

- Research which is freely available for redistribution 